\title{
Therapeutic options in the treatment and prevention of nonsteroidal anti-inflammatory drug-induced ulceration
}

\author{
MALCOLM C CHAMPION, MB, MRCP(UK), FRCPC
}

\begin{abstract}
This article reviews the current status of $\mathrm{H}_{2}$ receptor antagonists, omeprazole, sucralfate and misoprostol as therapeutic options for the prophylaxis and treatment of nonsteroidal anti-inflammatory drug (NSAID)-induced gastrointestinal ulceration. The efficacy of the $\mathrm{H}_{2}$ receptor antagonists appears to be restricted to prophylaxis and treatment of NSAID-induced duodenal ulcer disease. Omeprazole may have a place in the future treatment of NSAID-induced gastric ulcers. However, more studies are necessary to examine this drug's efficacy in both the prophylaxis and treatment of NSAID-induced ulceration. Sucralfate improves symptoms, but does not appear to have any effect on improving gastric mucosal damage when compared to placebo. It may, however, be useful in the treatment of NSAID-induced duodenal ulcers. Misoprostol is effective in both the prophylaxis and treatment of NSAID-induced gastric ulcers; however, its exact role in the prophylaxis and treatment of NSAID-induced duodenal ulcers remains to be defined. Can J Gastroenterol 1990;4(3):113-119
\end{abstract}

Key Words: $\mathrm{H}_{2}$ receptor antagonists, Misoprostol, NSAIDs, Omeprazole, Sucralfate, Ulcer

\section{Options thérapeutiques dans le traitement et la prévention de} l'ulcération provoquée par les anti-inflammatoires non stéroïdiens

RESUME: Cet article examine le statut présent des antagonistes du récepteur $\mathrm{H}_{2}$, l'oméprazole, le sucralfate et le misoprostol, comme choix thérapeutiques indiqués dans la prévention et le traitement de l'ulcération gastro-intestinale provoquée par les anti-inflammatoires non stéroïdiens. L'efficacité des anti- $\mathrm{H}_{2}$ semble se limiter à la prophylaxie et au traitement de l'ulcère gastro-duodénal provoqué par les AINS. L'oméprazole a peut-être sa place dans le traitement à

Division of Gastroenterology, Ottawa Civic Hospital, Ottawa, Ontario

Correspondence and reprints: Dr Malcolm C Champion, Ottawa Civic Hospital,

Division of Gastroenterology, 1053 Carling Avenue, Ottawa, Ontario K1Y 4E9
$\mathrm{T}$ HIS REVIEW ARTICLE DISCUSSES therapeutic options in the prophylaxis and treatment of NSAID. induced damage and ulceration to the gastrointestinal mucosa. The following drugs are reviewed: $\mathrm{H}_{2}$ receptor antagonists, omeprazole, sucralfate and misoprostol. The studies cited in this paper are controlled comparative studies published as full manuscripts. Open uncontrolled studies and studies reported only in abstract form will not be reviewed.

Nonsteroidal anti-inflammatory drug (NSAID)-induced ulceration occurs more commonly in the antrum and the prepyloric area of the stomach. It also occurs more commonly in women and elderly patients (1-3). McCarthy (4) estimated crude prevalence of gastric ulcers as $13 \%$ for NSAID users with arthritis compared with $0.28 \%$ in the normal population. This yielded an increased relative risk of 46 for developing gastric ulcer in patients taking NSAIDs. In addition, the crude prevalence of duodenal ulcer was estimated as $11 \%$ in NSAID users compared with $1.2 \%$ in the normal population. The relative risk of 
venir des ulcères gastriques provoqués par les AINS. Néanmoins, il est nécessaire d'effectuer d'autres études pour déterminer l'efficacité de cette substance, à la fois dans la prophylaxie et le traitement de cette affection. Le sucralfate soulage les symptômes mais ne semble entraîner aucune amélioration des lésions de la muqueuse gastrique comparé au placebo. Il peut toutefois s'avérer utile dans le traitement des ulcères duodénaux provoqués par les AINS. Le misoprostol est cependant efficace à la fois dans la prophylaxie et le traitement des ulcères gastriques provoqués par les AINS; son rôle exact dans la prophylaxie et le traitement des ulcères gastro-duodénal reste à définir. duodenal ulceration in patients taking NSAIDs was determined as eight times that of the normal population. Thus, if NSAID use is a causal factor, the user is six times more likely to develop a gastric versus duodenal ulcer as a consequence of NSAID therapy.

The etiology of the ulcer must be considered when determining the appropriate therapy for both prophylaxis and treatment of NSAID-induced ulceration. The NSAID-induced ulcer has an etiology and pathophysiology which is different from that of the acidmediated ulcer. In a recent review, Roth and Bennett (5) summarized this difference as an NSAID-induced ulcer being mediated by prostaglandin deficiency secondary to the cyclooxygenase inhibition of the NSAID. This deficiency results in decreased mucosal defences of the gastric and duodenal mucosa. Prostaglandins have been shown to be important in the production of bicarbonate and mucus and in maintaining mucosal bloodflow, which are significant components of gastrointestinal mucosal defence mechanisms. An acidmediated ulcer is due to a combination of excess acid, particularly in the duodenum, and decreased resistance of mucosal defences, particularly in the stomach.

Drugs which are known to act on the stomach should also be taken into consideration when choosing therapy, since NSAIDs inflict the majority of their damage in the stomach.

\section{$\mathrm{H}_{2}$ RECEPTOR ANTAGONISTS}

The following $\mathrm{H}_{2}$ receptor antagonists wili be discussed: cimetidine, in relation to both prevention and treatment; and ranitidine, in relation to prevention only.

Treatment: A study conducted by
Loludice and colleagues (6) demonstrated in 70 patients that cimetidine healed NSAID-induced ulcers compared to placebo. However, NSAID therapy was discontinued prior to patients being randomized to either cimetidine or placebo.

O'Laughlin and colleagues (7) compared cimetidine $300 \mathrm{mg}$ qid to placebo in 18 patients with NSAID-induced gastric ulcers. In both groups antacids were allowed as needed. NSAID therapy was continued during this study. The number of patients with a healed gastric ulcer after eight weeks was not significantly different in the two groups: cimetidine $56 \%$ (five of nine) versus placebo $44 \%$ (four of nine). The smaller gastric ulcers (less than $5 \mathrm{~mm}$ in diameter) showed significantly better healing than the larger ulcers. In addition, there was no significant difference in the relief of epigastric pain when cimetidine was compared to placebo.
In a study conducted by Davies and colleagues (8), 27 patients with NSAID-induced ulcers were randomized to either cimetidine $400 \mathrm{mg}$ qid or placebo for six weeks. NSAID was continued and there was no significant difference in the healing of ulcers or in antacid or analgesic consumption in either group over the six week period. No significant difference was found in the healing of either gastric ulcers or duodenal ulcers in this study, ie, cimetidine healed two of three duodenal ulcers and seven of 10 gastric ulcers; placebo healed two of three duodenal ulcers, and four of seven gastric ulcers.

In a double-blind, long term evaluation of cimetidine therapy in NSAID gastropathy, Roth and colleagues (9) compared cimetidine to placebo in both short term healing and long term maintenance therapy. One hundred and four patients with NSAID-induced mucosal lesions, ie, gastritis and erosions, but no ulcers, were randomized to either cimetidine $300 \mathrm{mg}$ qid or placebo. Of patients randomized to cimetidine and placebo, $56 \%$ (22 of 43 ) and $52 \%$, respectively, showed progression of endoscopic lesions during the eight week short term phase (Figure 1). Thirty-nine patients whose endoscopic scores improved were then randomized to a 10 month main-

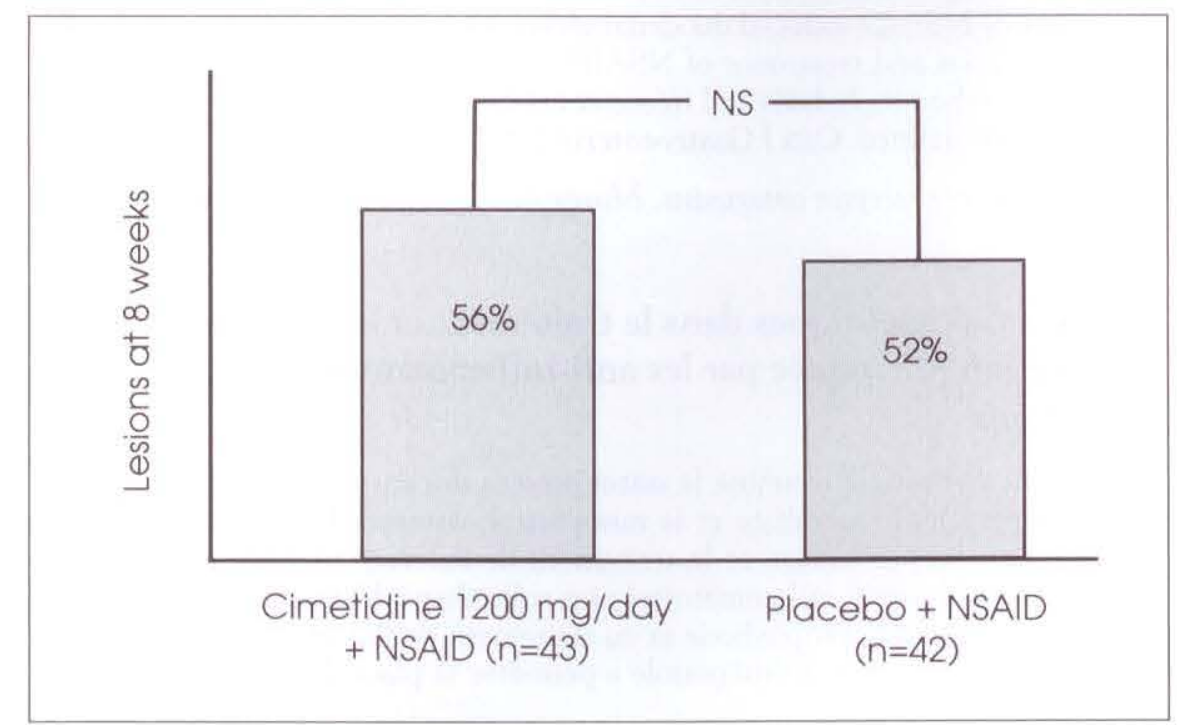

Figure 1) Progression of NSAID-induced gastrointestinal damage with cimetidine. NS Not significant; $n$ Number of patients. (Reproduced with permission from Roth SH, Bennett RE, Mitchell CS, Hartman RJ. Arch Intern Med 1987;147:1798-801). (C) 1987, AMA 


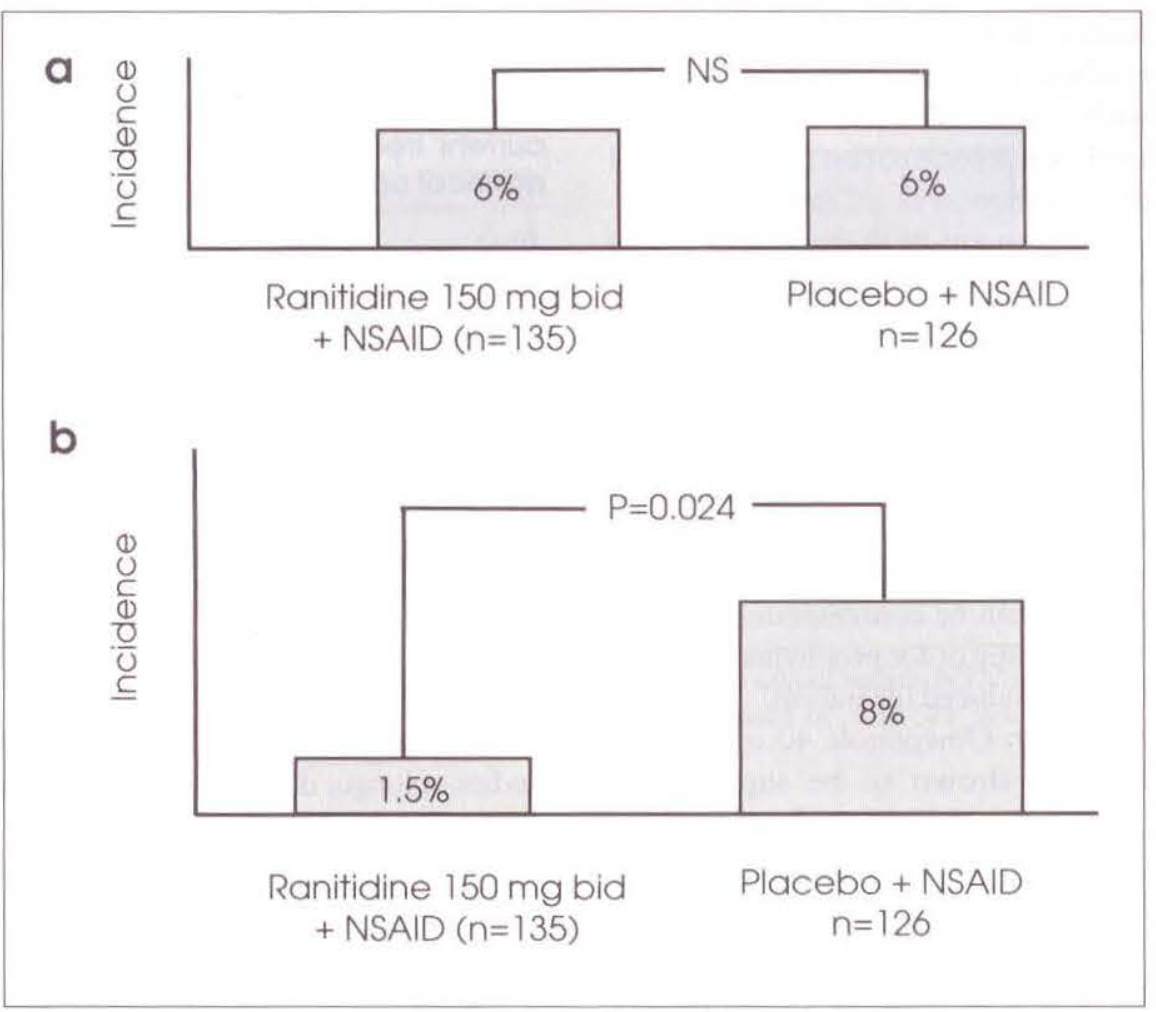

Figure 2)a NSAID-induced gastric ulceration. b NSAID-induced duodenal ulceration. Duration of treatment was eight weeks. NS Not significant; $n$ Number of patients. (Adapted with permission from Ehsanullah RSB, Page MC, Tildesley G, Wood JR. Br Med J 1988;297:1017-21)

tenance regimen of either cimetidine $400 \mathrm{mg}$ at bedtime or placebo. Fifty per cent (seven of 14) of placebo-treated and $42 \%$ (five of 12 ) of cimetidinetreated patients showed progression of lesions during the maintenance phase. There were no data in terms of symptoms in this study.

Prevention: In a recently published study, Robinson and colleagues (10) examined the efficacy of ranitidine versus placebo in the prophylaxis of NSAIDinduced gastrointestinal mucosal damage. After a normal endoscopy, NSAIDs were given and 144 patients randomized to receive either ranitidine $150 \mathrm{mg}$ bid or placebo. No significant difference was found in the degree of gastric mucosal damage when ranitidine was compared to placebo. The degree of maximal mucosal injury in the duodenum, however, was significantly less with ranitidine compared with placebo $(P=0.01)$. After four weeks of NSAID therapy, four of 57 patients $(70 \%)$ on placebo developed duodenal ulcers compared with none of the 62 patients taking ranitidine. In addition, no statistically significant differences were found between ranitidine and placebo groups with respect to symptoms of peptic distress or incidence of gastrointestinal pain. Furthermore, there was no association between symptoms and degree of mucosal damage documented by endoscopy.

In the second study, by Ehsanullah and colleagues (11), ranitidine $150 \mathrm{mg}$ bid was compared with placebo in patients on NSAIDs for arthritis. After a normal endoscopy, 297 patients were randomized to either the ranitidine or placebo groups. NSAID therapy was continued and endoscopy repeated after eight weeks. No significant difference was found between the two groups with respect to incidence of gastric ulcers, which was $6 \%$. Duodenal ulceration developed in 1.5\% (two of 135) of patients taking ranitidine compared to $8 \%$ (10 of 126 ) taking placebo (Figure 2). However, ranitidine was not more effective than placebo in preventing development of grade 2 to grade 4 lesions (multiple erosions with or without an ulcer) in the duodenum: ranitidine $12 \%$ (17 of 137$)$; placebo $13 \%$ (17 of 126). Patients with a previous history of ulceration appeared to be more prone to develop ulcers in this study. There was no significant difference in upper gastrointestinal symptoms when ranitidine was compared to placebo.

In a large, double-blind, endoscopically controlled study, Stalnikowicz and colleagues (12) compared cimetidine to placebo in 191 patients with acute musculoskeletal disorders for a period of one week. The effect of two doses of cimetidine, $400 \mathrm{mg}$ at bedtime and $400 \mathrm{mg}$ bid, was compared to placebo in the prevention of indomethacin-induced mucosal damage (50 $\mathrm{mg}$ tid). Endoscopy was performed before and after five to seven days of treatment. The mean total damage score of all gastric and duodenal lesions in the placebo-treated patients and in those taking cimetidine $400 \mathrm{mg}$ at bedtime were significantly higher than that of the cimetidine $400 \mathrm{mg}$ bid group $(\mathrm{P}=0.0122)$. Analysis of the regional total lesion scores demonstrated that damage to antral mucosa was slightly reduced by cimetidine, although not significantly. Significant $(\mathrm{P}=0.0004)$ protection, however, was afforded to the duodenal mucosa in the cimetidine $400 \mathrm{mg}$ bid group. No significant difference was found in the gastric mucosal lesion scores. Cimetidine did not ameliorate gastrointestinal symptoms induced by indomethacin when compared with placebo during this one week study.

Side effects: The $\mathrm{H}_{2}$ receptor antagonists have a low incidence of side effects. Cimetidine interferes with the metabolism of drugs which are processed by the cytochrome $\mathrm{P} 450$ system in the liver and has been demonstrated to increase significantly the half-life of Valium (diazepam; Roche), Coumadin (warfarin; Du Pont) and phenytoin. Other side effects related to cimetidine are diarrhea and constipation (13). Ranitidine has a very low incidence of side effects, the main complaint being headache (14). It has not been shown to interfere significantly with the cytochrome P450 mechanism in the liver. 
Summary: The $\mathrm{H}_{2}$ receptor antagonists cimetidine and ranitidine have not been shown to improve NSAID-induced gastrointestinal symptoms compared to placebo, nor have they demonstrated any efficacy in the prophylaxis and treatment of NSAID. induced gastric ulcers. Cimetidine and ranitidine have, however, been shown to be effective in the prophylaxis of NSAID-induced duodenal ulcer disease. Efficacy in the treatment of NSAID-induced duodenal ulcer disease requires further examination (15).

\section{OMEPRAZOLE}

Omeprazole works by blocking the enzyme $\mathrm{H}^{+}, \mathrm{K}^{+}$-ATPase in the parietal cell and thus inhibiting gastric acid production. This results in a more potent acid suppression than that conferred by the $\mathrm{H}_{2}$ receptor antagonists. Omeprazole has recently been approved in Canada for the treatment of duodenal ulcers, gastric ulcers, reflux esophagitis and Zollinger-Ellison syndrome.

To date there has only been one study published in which NSAID-induced ulceration, as a subset of a larger study, has been examined (16). In this study of 602 patients, two doses of omeprazole were compared to ranitidine in the healing of benign gastric ulcers. In the 68 patients $(11.3 \%)$ with NSAID-induced ulcers the NSAID was continued during the study.

Twenty-two patients were randomized to omeprazole $20 \mathrm{mg}$ once a day, 23 to omeprazole $40 \mathrm{mg}$ once a day, and 23 to ranitidine $150 \mathrm{mg}$ bid. At week 8 , $95 \%$ of ulcers healed with omeprazole $40 \mathrm{mg}$ once a day, $82 \%$ with omeprazole $20 \mathrm{mg}$ once a day, and $53 \%$ with ranitidine $150 \mathrm{mg}$ bid (Table 1). Omeprazole $40 \mathrm{mg}$ a day was superior to ranitidine in healing gastric ulcers $(\mathrm{P}=0.02)$. There were no data regarding symptom improvement in the subsection of patients taking NSAIDs.

Side effects: Omeprazole has a low incidence of side effects with the main complaints being nausea, diarrhea and abdominal discomfort (17). There is, however, concern about the long term safety of omeprazole. This is because raised serum gastrin levels have been found in both animal and human studies. Animal toxicologic studies with omeprazole have reported localized enterochromaffin-like cell proliferation and in some cases carcinoid tumours in the stomachs of rats after two years of treatment with very large doses (18). These changes in serum gastrin and enterochromaffinlike cells are thought to be speciesdependent and are not likely to be important clinically in short term use in humans. Considerably more clinical experience with omeprazole is required before it can be contemplated for long term therapy or for prophylaxis against NSAID-induced ulceration.

Summary: Omeprazole $40 \mathrm{mg}$ once a day was shown to be superior to ranitidine $150 \mathrm{mg}$ bid in healing NSAID-induced gastric ulcers in a small number of patients when the NSAID was continued. There are no data on the treatment of NSAID-induced duodenal ulcers or the use of omeprazole in preventing mucosal damage due to NSAIDs. It appears that omeprazole $40 \mathrm{mg}$ once a day may have a role in the treatment of NSAID-induced gastric ulcers. Because of concerns about the long term safety of omeprazole and the fact that no studies regarding prevention have been conducted to date, omeprazole is not recommended in the prophylaxis of NSAID-induced ulceration.

\section{SUCRALFATE}

Sucralfate is a sulphated polysaccharide that has demonstrated efficacy in the treatment of both acid-mediated duodenal ulcer disease and gastric ulcer disease $(19,20)$. In the presence of acid, sucralfate forms a chemical complex that binds to the ulcer site to establish a protective barrier, thereby blocking the back diffusion of acid. In addition, sucralfate appears to have a direct inhibitory effect on the action of pepsin and bile on the gastric mucosa. The synthesis and release of prostaglandin $\mathrm{E}_{2}$ from the mucosa (21) has been shown to increase with sucralfate, possibly due to the aluminum component of sucralfate. (Aluminum-containing antacids have been shown to have a similar action.) Sucralfate has been
TABLE 1

Proportion of patinets with healed ulcers among patients receiving concurrent treatment with NSAIDs (per protocol approach)

\begin{tabular}{lll}
\hline Drug & 4 weeks & 8 weeks \\
\hline $\begin{array}{l}\text { Omeprazole } \\
20 \mathrm{mg}\end{array}$ & $11 / 18(61)$ & $14 / 17(82)$ \\
$\begin{array}{l}\text { Omeprazole } \\
40 \mathrm{mg}\end{array}$ & $17 / 21(81)$ & $21 / 22(95)$ \\
Ranitidine & $6 / 19(32)$ & $9 / 17(53)$ \\
\hline
\end{tabular}

Values are number healed/total (\%). (Reproduced with permission from Walan A. Bader J.P. Classen $M$, et al. N Engl J Med 1989:320:69-75)

shown to protect the gastric mucosa in the short term administration of acetyl. salicylic acid (ASA) (22). In two studies of longer duration (six days and two weeks), however, sucralfate did not protect the gastric mucosa against ASA (23).

Only two controlled studies have been published on the efficacy of sucralfate in NSAID-induced ulceration; both dealt with efficacy in relation to treatment rather than prevention.

In a study conducted by Manniche and colleagues (15), 67 patients with rheumatic disease and NSAID-induced ulceration were given either ranitidine $150 \mathrm{mg}$ bid or sucralfate $1 \mathrm{~g}$ qid for nine weeks. Fifty-one patients had a diagnosis of duodenal ulcer, 14 gastric ulcer, and two had both gastric and duodenal ulcers. The patients in each treatment arm were then further divided into two treatment groups: one NSAID discontinued, and one continued NSAID use. Patients who were not healed by nine weeks were crossed over to the other treatment modality.

The efficacy of these drugs was most apparent in the duodenum, when the NSAID was discontinued. At nine weeks, in patients who stopped their NSAIDs, 92 and $86 \%$ of the duodenal and gastric ulcers healed, respectively.

In the group that continued NSAID use, $82 \%$ of duodenal but only $20 \%$ of gastric ulcers healed. Although this study was well performed, the large number of duodenal ulcers raises the question of whether some of these ulcers were acid-mediated rather than NSAID-mediated. With regard to the efficacy of either ranitidine or sucral- 


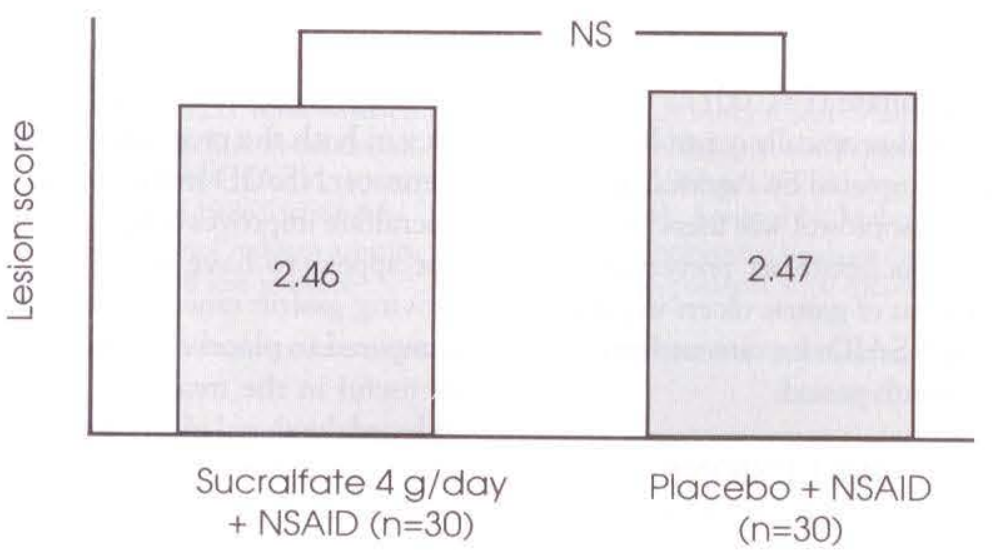

Figure 3) Reduction of NSAID-induced gastric mucosal damage with sucralfate. NS Not significant; $n$ Number of patients. (Reproduced with permission from Caldwell JR, Roth SH, Wu WC, et al. Am J Med 1987;83 [Suppl 3B]:74-82)

fate on the healing of gastric ulcer, it is difficult to come to a conclusion, due to the small number of subjects who had gastric ulcers.

Caldwell and colleagues (24) evaluated 143 symptomatic patients on long term NSAIDs, of which only 60 had mucosal damage. Patients were randomized to either sucralfate $1 \mathrm{~g}$ qid or placebo; the NSAID was continued. In the 60 patients with endoscopic mucosal damage, results were expressed as lesion scores after four weeks of treatment. The lesion scores were unchanged in the placebo group and showed only a small change from baseline in the mean lesion scores ( 3.5 to 2.46) in those given sucralfate $(\mathrm{P}<0.005)$ (Figure 3). When sucralfate was compared to placebo, there was no statistical difference in the mean change of lesion scores.

Sucralfate was effective in decreasing symptoms compared to placebo in patients taking long half-life and non salicylated NSAIDs. Patients taking salicylates and short half-life NSAIDs did not benefit. There was a significant decrease in intensity, but not frequency, of mean symptom scores for all NSAIDs. No correlation was found between mucosal damage and symptom outcome $(\mathrm{P}<0.03)$.

In the open-label, six month, follow-up study, sucralfate ( $1 \mathrm{~g}$ bid) was administered (titratable to $1 \mathrm{~g}$ qid), as well as antacids for pain. Sucralfate was evaluated for its effect on symptoms and gastric lesion scores in patients receiving all types of NSAIDs. At the end of the six months there were significant decreases in mean symptom scores for all NSAIDs $(\mathrm{P}=0.001)$. Of the original 60 patients with mucosal damage, 36 were monitored and given repeat endoscopies at the end of the study. No significant differences were found in the mean mucosal lesion scores from the end of the double-blind phase to the end of long term therapy. There was no placebo arm in this six month maintenance study.

Side effects: Sucralfate is a nonsystemic drug with a low incidence of side effects. The most common complaint with sucralfate is constipation. It has been shown to decrease the absorption of a variety of drugs including tetracycline, phenytoin, cimetidine and digoxin (25). One study demonstrated raised aluminum levels in patients taking therapeutic doses (ie, $1 \mathrm{~g}$ qid) of sucralfate. The significance of raised aluminum levels in relation to Alzheimer's disease remains controversial (26).

Summary: Sucralfate has been shown to be effective compared to placebo in improving symptoms for the milder NSAIDs. It has not, however, shown efficacy in improving NSAID-induced gastric damage compared to placebo. Regardless of whether NSAIDs were continued, sucralfate was found to be as effective as ranitidine in healing
NSAID-induced duodenal ulcers. There are no controlled studies published on the efficacy of sucralfate in the prophylaxis of NSAID-induced mucosal damage or ulceration.

\section{MISOPROSTOL}

The prostaglandins have been shown to have antacid, acid antisecretory (27), and mucosal protective effects (28). The mucosal protective effects of the prostaglandins are due to increased mucus and bicarbonate secretion, resulting in an increase in the thickness of the mucus layer. In addition, the prostaglandins appear to maintain or improve gastric mucosal bloodflow, thereby maintaining cell integrity. This action is evident with the $E_{1}$ and $E_{2}$ prostaglandins.

Misoprostol is a synthetic methyl ester analogue of prostaglandin $E_{1}$, which has been recently approved in Canada for the prophylaxis and treatment of NSAID-induced gastric ulcers. A prostaglandin $E_{2}$ analogue, enprostil (Syntex), has undergone clinical trials (29) but has not yet been approved in Canada.

Clinical studies: In clinical studies, misoprostol has been shown to decrease gastrointestinal blood loss significantly in patients with osteoarthritis taking ASA (30). Moreover, misoprostol is the only drug which has been shown to be effective compared to placebo in the prophylaxis and treatment of NSAID. induced gastric ulceration (31). It appears to be effective in the duodenum but this requires further clarification. Misoprostol has also been shown to significantly improve mucosal damage and heal gastric ulcers compared to placebo in patients with rheumatoid arthritis while the NSAID (ASA) was continued (32).

Comparative studies: There has been only one study comparing the mucosal protective effect of misoprostol to cimetidine (33). This double-blind, placebo controlled study demonstrated that misoprostol prevented tolmetininduced gastric injury in $93.1 \%$ of healthy subjects compared to $63 \%$ for cimetidine and $26.7 \%$ for placebo. Misoprostol was also superior when directly compared to cimetidine (not significant). In the duodenum, both 
misoprostol and cimetidine were highly protective compared to placebo.

To study and compare the effects of misoprostol, sucralfate and placebo in the prevention of ASA-induced ulceration, 30 healthy volunteers partici. pated in a double-blind study (23). Volunteers with endoscopically normal mucosa were randomized to receive ASA $650 \mathrm{mg}$ qid with either misoprostol $200 \mu \mathrm{g}$ qid, sucralfate $1 \mathrm{~g}$ qid, or placebo. A therapeutic success was defined as less than 10 hemorrhages or erosions. All patients receiving misoprostol were deemed a success (10 of 10) compared to $20 \%$ receiving sucralfate (two of 10) and none of the 10

\section{REFERENCES}

1. Langman MJS. Epidemiologic evidence on the association between peptic ulceration and anti-inflammatory drug use. Gastroenterology 1989;96:640-6.

2. Langman MJS. Ulcer complications and nonsteroidal anti-inflammatory drugs. Am J Med 1988;84 (Suppl 2A):15-9.

3. Griffin MR, Ray WA, Schaffner W. Non-steroidal anti-inflammatory drug use and death from peptic ulcer in elderly persons. Ann Intern Med 1988; 109:359-63.

4. McCarthy DM. Nonsteroidal antiinflammatory drug-induced ulcers: Management by traditional therapies. Gastroenterology 1989;96:662-74.

5. Roth SH, Bennett RE. Nonsteroidal anti-inflammatory drug gastropathy. Recognition and response. Arch Intern Med 1987;147: 2093-100.

6. Loludice TA, Saleem T, Lang JA. Cimetidine in the treatment of gastric ulcer induced by steroidal and nonsteroidal anti-inflammatory agents. Am J Gastroenterol 1981;75:104-10.

7. O'Laughlin JC, Silvoso GK, Ivey KJ. Resistance to medical therapy of gastric ulcers in rheumatic disease patients taking aspirin. A double-blind study with cimetidine and follow-up. Dig Dis Sci 1982;27:976-80.

8. Davies J, Collins AJ, Dixon A St J. The influence of cimetidine on peptic ulcer in patients with arthritis taking anti-inflammatory drugs. $\mathrm{Br}$ ] Rheumatol 1986;25:54-8.

9. Roth SH, Bennett RE, Mitchell CS, Hartman RJ. Cimetidine therapy in nonsteroidal anti-inflammatory drug gastropathy. Double-blind long-term evaluation. Arch Intern Med 1987;147:1798-801. patients receiving placebo. Overall, misoprostol was found to be significantly superior when compared to placebo and to sucralfate $(\mathrm{P}=0.001)$.

In an endoscopically controlled study, recently completed by Agrawal and colleagues, misoprostol was found to be superior to sucralfate in preventing the development of gastric ulcers in patients receiving NSAIDs for osteoarthritis over a three month period.

\section{CONCLUSIONS}

The efficacy of $\mathrm{H}_{2}$ receptor antagonists appears to be restricted to the prophylaxis and treatment of NSAIDinduced duodenal ulcer disease. Omep-

10. Robinson MC, Griffin JW, Bowers J, et al. Effect of ranitidine on duodenal mucosal damage induced by nonsteroidal anti-inflammatory drugs. Dig Dis Sci 1989;34:424-8.

11. Ehsanullah RSB, Page MC. Tildesley G, Wood JR. Prevention of gastroduodenal damage induced by non-steroidal anti-inflammatory drugs: Controlled trial of ranitidine. Br Med ] 1988;297:1017-21.

12. Stalnikowicz R, Pollak D, Eliakim A, et al. Cimetidine decreases indomethacin induced duodenal mucosal damage in patients with acute musculoskeletal disorders. Gut 1988;29:1578-82.

13. Cimetidine Product Monograph. Mississauga: Smith, Kline and French, 1985.

14. Ranitidine Product Monograph. Toronto: Glaxo Canada Inc, 1989.

15. Manniche C, Malchow-Moller A, Andersen JR, et al. Randomized study of the influence of non-steroidal antiinflammatory drugs on the treatment of peptic ulcer in patients with rheumatic disease. Gut 1987:28:226-9.

16. Walan A, Bader J-P, Classen M, et al. Effect of omeprazole and ranitidine on ulcer healing and relapse rates in patients with benign gastric ulcer. N Engl J Med 1989;320:69-75.

17. Omeprazole Product Monograph. Mississauga: Astra Pharma Inc, 1989.

18. Hakanson R, Sundler F, Carlsson E, Mattsson H, Larsson H. Proliferation of enterochromaffin-like (ECL) cells in the rat stomach following omeprazole treatment. Hepatogastroenterology $1985 ; 32: 48-9$

19. Lam SK, Lau WY, Lai CL, et al. Efficacy of sucralfate in corpus, prepyloric, and ulcer-associated gastric ulcers. Am J Med 1985;79 razole may have a place in the future treatment of NSAID-induced gastric ulcers; however, more studies are necessary to examine this drug's efficacy in both the prophylaxis and treatment of NSAID-induced ulceration. Sucralfate improves symptoms but does not appear to have any effect on improving gastric mucosal damage when compared to placebo. It may, however, be useful in the treatment of NSAID. induced duodenal ulcers. Misoprostol is effective in both the prophylaxis and treatment of NSAID-induced gastric ulcers. Its exact role in the prophylaxis and treatment of NSAID-induced duodenal ulcers remains to be defined.

(Suppl 2C):24-31

20. Martin F, Farley A, Gagnon M, Bensemana D. Comparison of the healing capacities of sucralfate and cimetidine in the short term treatment of duodenal ulcer: A double blind randomized trial. Gastroenterology 1982:82:401-5.

21. Tarnawski A, Hollander D, Krause WJ, Zipser RD, Stachura J, Gergely H. Does sucralfate affect the normal gastric mucosa? Histologic, ultrastructural, and functional assessment in the rat. Gastroenterology 1986;90:893-905.

22. Stern AI, Ward F, Hartley G. Protective effect of sucralfate against aspirininduced damage to the human gastric mucosa. Am J Med 1987;83 (Suppl 3B):83-5.

23. Lanza F, Peace K, Gustitus L, Rack MF, Dickson B. A blinded endoscopic comparative study of misoprostol versus sucralfate and placebo in the prevention of aspirin-induced gastric and duodenal ulceration. Am J Gastroenterol 1988;83:143-6..

24. Caldwell JR, Roth SH, Wu WC, et al. Sucralfate treatment of non-steroidal anti-inflammatory drug-induced gastrointestinal symptoms and mucosal damage. Am J Med 1987;83 (Suppl 3B): 74-82.

25. Sucralfate Product Monograph. Montreal: Nordic Laboratories Inc, 1987.

26. Pai S, Melethil S, Cuddy P, Hall T. Elevation of serum aluminum in humans on a two-day sucralfate regimen. J Clin Pharmacol 1987;27:213-5.

27. Dajani EZ. Perspective on the gastric antisecretory effects of misoprostol in man. Prostaglandins 1987;33 (Suppl):68-77.

28. Dajani EZ. Overview of the mucosal 
protective effects of misoprostol in man. Prostaglandins 1987;33

(Suppl):177-29.

29. Lauritsen K, Laursen LS, Havelund T, Bytzer P, Svendsen LB, Rask-Madsen I. Enprostil and ranitidine in duodenal ulcer healing: Double-blind comparative trial. Br Med J 1986;292:864-6.

30. Ryan JR. Misoprostol reduces aspirininduced fecal blood loss in osteo- arthritic patients. Adv Prostagland Gastroenterol 1986.

31. Graham DY, Agrawal N, Roth SH. Prevention of NSAID-induced gastric ulcer with misoprostol: Multicentre, double-blind, placebo-controlled trial. Lancet 1988; ii: $1277-80$.

32. Roth SH, Agrawal N, Mahowald M, et al. Misoprostol heals gastroduodenal injury in patients with rheumatoid arthritis receiving aspirin. Arch Intern Med 1989;149:775-9.

33. Lanza FL, Aspinall RL, Swabb EA, Davis RE, Rack MF, Rubin A. Doubleblind, placebo-controlled endoscopic comparison of the mucosal protective effects of misoprostol versus cimetidine on tolmetin-induced mucosal injury to the stomach and duodenum. Gastroenterology 1988;95:289-94. 


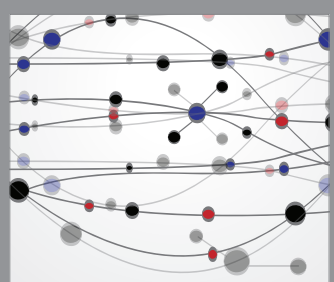

The Scientific World Journal
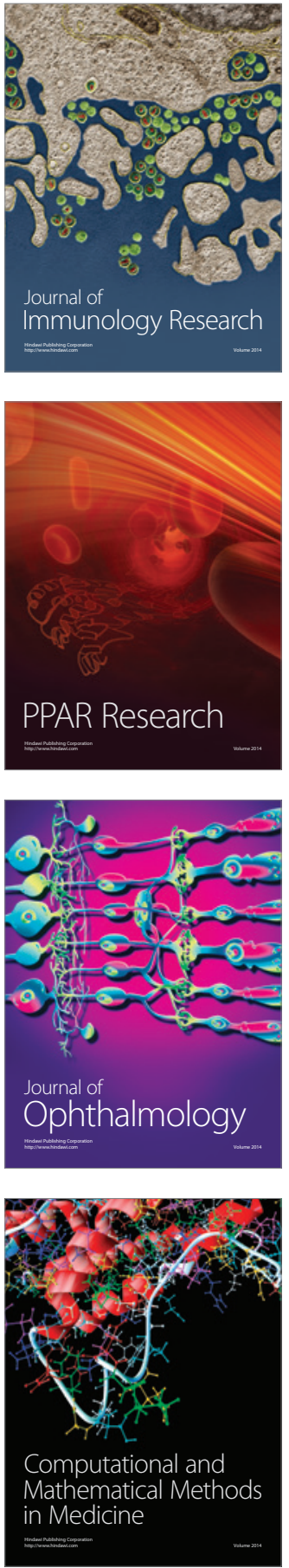

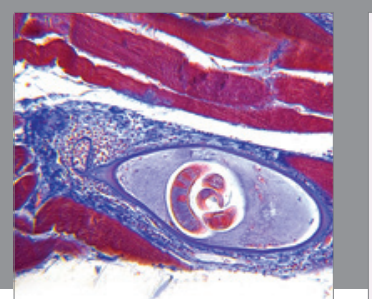

Gastroenterology Research and Practice

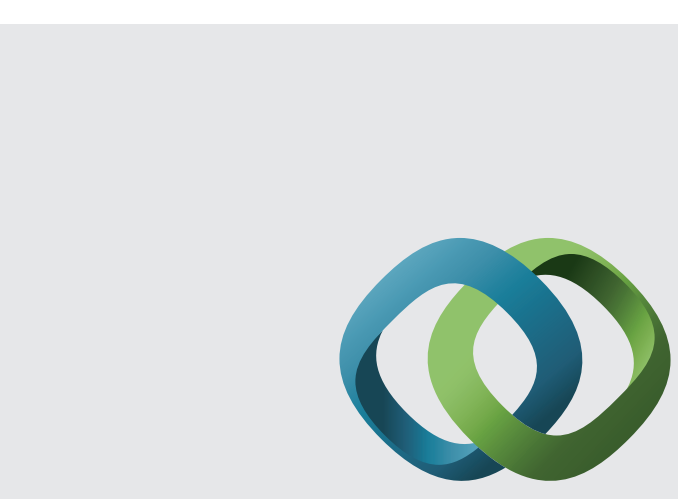

\section{Hindawi}

Submit your manuscripts at

http://www.hindawi.com
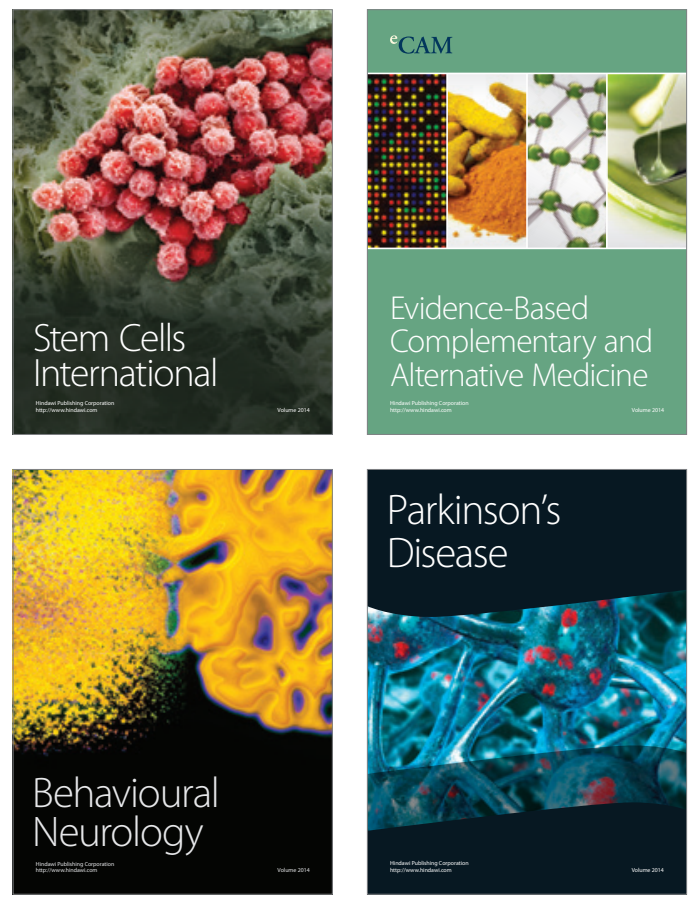
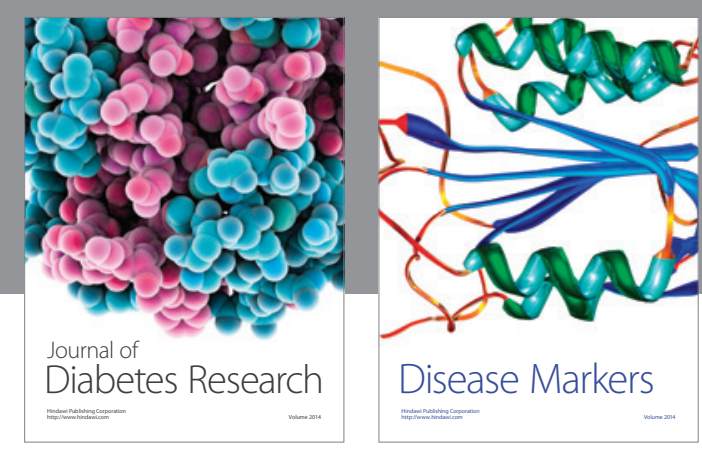

Disease Markers
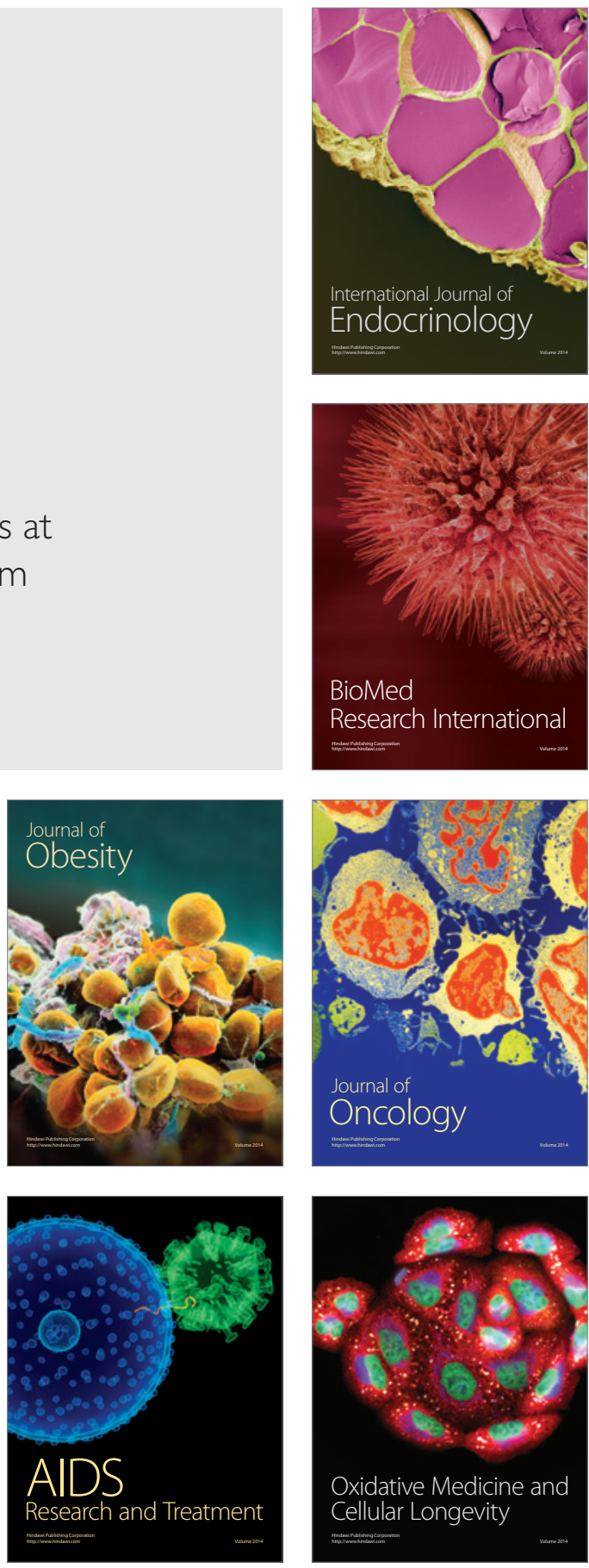